$\begin{array}{ll}\text { Research Square } & \begin{array}{l}\text { Preprints are preliminary reports that have not undergone peer review. } \\ \text { They should not be considered conclusive, used to inform clinical practice, } \\ \text { or referenced by the media as validated information. }\end{array}\end{array}$

\title{
Impact of Body Mass Index on the Mortality of Critically III Patients Admitted to the Intensive Care Unit: An Observational Study
}

\author{
Ata Mahmoodpoor \\ Tabriz University of Medical Sciences \\ Fahimeh Karrubi \\ Tabriz University of Medical Sciences \\ Mohammad-Salar Hosseini \\ Tabriz University of Medical Sciences \\ Afshin Iranpour \\ Al garhoud private hospital \\ Sarvin Sanaie ( $\sim$ sarvin_so2000@yahoo.com ) \\ Tabriz University of Medical Sciences
}

\section{Research article}

Keywords: Body mass index, ill patients, intensive care units, mortality, waist circumference

Posted Date: June 3rd, 2020

DOI: https://doi.org/10.21203/rs.3.rs-31401/v1

License: (c) (i) This work is licensed under a Creative Commons Attribution 4.0 International License. Read Full License 


\section{Abstract}

Background: Obesity, a wide-ranging disorder all around the world, is associated with significant morbidity and mortality in the general population. Regarding the present controversies, this study aims to evaluate the possible association of body mass index (BMI) and mortality in patients admitted to intensive care units.

Methods: During this cross-sectional study, all patients admitted to the intensive care unit of two university affiliated hospitals in northwest of Iran from November 2017 to March 2019 were enrolled. The demographic characteristics of patients, length of stay in the intensive care unit and hospital, organ failure, mortality, duration of mechanical ventilation and vasopressor-therapy, type of nutrition, the occurrence of nosocomial infection, type of admission (medical, surgical, trauma) were recorded for all patients. According to the WHO classification of BMI, patients were divided into the six groups, and the data were analyzed accordingly.

Results: Of the 502 patients studied, 267 were male (53.2\%) and 235 were female (46.8\%).

The highest mortality rate was observed among the obesity class II patients $(35<\mathrm{BMI}<40)$ with $28.6 \%$, while the lowest rate was observed in the normalweight patients $(18.5<\mathrm{BMI}<25)$ with $3.9 \%$. The highest length of hospital stay was seen in patients with BMI > 30 with 12 days of hospitalizations. APACHE II and waist circumference had a statistically significant relationship with the mortality rate of patients $(P$-value $<0.001)$.

Conclusion: The current study showed that BMI could be related to mortality, regardless of waist circumference and APACHE II score. However, considering waist circumference and APACHE II score as confounding factors, BMI does not have a significant effect on mortality and only affect the morbidity of patients.

\section{Background}

Obesity is a severe multifactorial disorder that is strongly associated with several life-threatening complications [1, 2]. As a growing health concern, obesity affects $>2.1$ billion individuals around the world and is responsible for more than 3.4 million deaths each year [3, 4]. With the development of sedentary lifestyle, obesity is becoming more prevalent, especially in developing countries [4, 5]. There are various ways to define obesity [6]. The body fat is usually estimated by dividing body weight $(\mathrm{kg})$ by height ${ }^{2}(\mathrm{~m})$, which is called as Body Mass Index (BMI). Based on the World Health Organization (WHO) classification, BMI over 25 and over 30 are respectively considered as overweight and obese [7]. It is proven that overweight can play an underlying role in causing hypertension, diabetes, hyperlipidemia, cancer, and pulmonary disorders [8-11].

On the other hand, comorbidities have a determining impact on the prognosis of critically ill patients [12]. That is the reason why the scoring systems used in the survival assessment of critically ill ICU patients, including the Acute Physiology And Chronic Health Evaluation (APACHE) II and III, Simplified Acute Physiology Score (SAPS) II and Mortality probability models (MPM II), all have emphasized on underlying comorbidities by dedicating considerable scores [13, 14]. Hence, regardless of the direct impacts of obesity on critically ill patients' prognosis, obesity can lead to worsening of the conditions by triggering other serious health issues.

There is a substantial controversy regarding the effect of obesity on the mortality, morbidity, and the hospital length of stay (LOS) in critically ill patients admitted to ICU $[15,16]$. Meanwhile, as a merely adjustable risk factor, obesity could come handy in accurately assessing the prognosis of ICU-admitted patients and prevent a remarkable amount of ICU deaths. Therefore, this study aims to determine the association between the BMI and mortality of the critically ill patients admitted to the intensive care unit.

\section{Materials And Methods}

\section{Study Design and Population}

During the present cross-sectional study, all patients admitted to the intensive care unit of Shohada hospital and the general intensive care unit of Imam Reza hospital between November 2017 and March 2019 were included. Exclusion criteria consisted of having a previous history of admission to the intensive care unit, unwillingness to participation, and lack of complete height and weight records at the time of admission.

The following clinical data were recorded for all patients: age, gender, body mass index, APACHE II score, type of admission (medical, surgical, trauma), comorbidities, history of malignancy or immunodeficiency and diabetes, duration of stay in the intensive care unit, length of hospital stay, organ failure during the admission, based on the Sequential Organ Failure Assessment (SOFA) Score, covering the respiratory, cardiovascular, hepatic, renal and central nervous systems and coagulation, mortality rate, duration of mechanical ventilation or vasopressor-therapy, type of nutrition, site of infection (if present) and reintubation/extubation failure.

\section{Statistical Analysis}

Data were analyzed using SPSS16 software and reported as mean \pm standard deviation for the continuous variables, and percentage for discrete variables. For clinical information and differences between groups in categorical variables, chi-square and Fisher s exact tests were used. P-value among different BMI groups was analyzed using ANOVA. Quantitative and qualitative variables were analyzed using independent T-test, paired T-test and Chi-Square test respectively. A P-value of less than 0.05 was considered significant.

\section{Ethical Considerations}


Written consent was obtained from all of the patients or their next of kin. The study protocol was approved by the Ethics Committee of Tabriz University of Medical Sciences, which is in compliance with the Declaration of Helsinki. The patients' information was anonymous and analyzed in a coded format. No additional charges were paid by the patients at the end of the study, and the patients could abandon the study at any stage on personal desire.

\section{Results}

From the 525 medical records, 23 were excluded due to incomplete information. Among the 502 included patients, 267 (53.2\%) were men, and the mean age was $59.42 \pm 11.48$ years old. Among the whole population of the study, the total mean \pm SD for weight was $72.18 \pm 13.144 \mathrm{~kg}$, the total mean \pm SD for waist circumference was $85.03 \pm 8.545 \mathrm{~cm}$, and the median length of hospital stay and stay in intensive care unit were seven and four days, respectively. Seventy-six patients had a positive history of diabetes which 30 of them had type 1 diabetes. The mean \pm SD for the blood level of albumin was $3.46 \pm 0.26$.

According to the classification of the World Health Organization (WHO), patients were classified to six groups based on their BMI: Underweight (BMI< 18.5), normal-weight $(18.5 \leq \mathrm{BMI}<25)$, overweight $(25 \leq \mathrm{BMI}<30)$, obesity class I $(30 \leq \mathrm{BMI}<35)$, obesity class II $(35 \leq \mathrm{BMI}<40)$, and obesity class III $(40 \leq \mathrm{BMI})$ [17]. The highest mortality rate (28.6\%) was seen among the obesity class II group ( $35 \leq \mathrm{BMI}<40$ ), while the normal-weight group (18.5 $\leq \mathrm{BMI}<25)$ had the lowest mortality rate (3.9\%). The highest length of stay in hospital and ICU were both seen in the obesity class I group, while the normal-weight group had the lowest length in both. The underweight group had the highest history of malignancy among the study groups. The obesity class I group had the highest rate of reintubations, and the obesity class II group had the highest rate of extubation failure. Most of the admission types were medical, and most of the patients had enteral nutrition. The highest and lowest APACHE II score was observed in underweight and normal-weight groups, which was significant according to the ANOVA test. While the total mean of APACHE II score was $20.18 \pm 4.291$, the mean score among the patients with and without mortality was $30.21 \pm 3.22$, and $18.89 \pm 2.20$, respectively $(P$-value $<0.001)$. The chief demographic information of the patients and study outcomes, all are summarized in Table 1 .

Table 1

Demographic information of the included patients $(\mathrm{N}=502)$.

\begin{tabular}{|c|c|c|c|c|c|c|c|c|c|c|c|}
\hline \multirow[t]{3}{*}{ Group } & \multirow{3}{*}{$\begin{array}{l}\text { Body } \\
\text { mass } \\
\text { index } \\
(\mathrm{BMI})\end{array}$} & \multirow{3}{*}{$\begin{array}{l}\text { Number } \\
\text { of } \\
\text { patients }\end{array}$} & \multicolumn{2}{|l|}{ Gender } & \multirow{3}{*}{$\begin{array}{l}\text { Mortality } \\
\mathrm{N}(\%)\end{array}$} & \multirow{3}{*}{$\begin{array}{l}\text { Length of } \\
\text { hospital } \\
\text { stay } \\
\text { (Median) }\end{array}$} & \multirow{3}{*}{$\begin{array}{l}\text { Duration of } \\
\text { stay in the } \\
\text { intensive } \\
\text { care unit } \\
\text { (Median) }\end{array}$} & \multirow{3}{*}{$\begin{array}{l}\text { APACHE II } \\
\text { score } \\
\text { (Mean } \pm \\
\text { SD) }\end{array}$} & \multirow{3}{*}{$\begin{array}{l}\text { Hospital } \\
\text { infection } \\
\mathrm{N}(\%)\end{array}$} & \multirow{3}{*}{$\begin{array}{l}\text { History of } \\
\text { malignancy } \\
N(\%)\end{array}$} & \multirow{3}{*}{$\begin{array}{l}\text { Reintı } \\
\mathrm{N}(\%)\end{array}$} \\
\hline & & & Female & Male & & & & & & & \\
\hline & & & $N(\%)$ & $N(\%)$ & & & & & & & \\
\hline Underweight & $\begin{array}{l}\text { Less } \\
\text { than } \\
18.5\end{array}$ & 39 & $\begin{array}{l}7 \\
(17.9)\end{array}$ & $\begin{array}{l}32 \\
(82.1)\end{array}$ & $8(20.5)$ & 6 & 6 & $\begin{array}{l}22.08 \pm \\
6.247\end{array}$ & $18(46.2)$ & $24(61.5)$ & $7(17$. \\
\hline $\begin{array}{l}\text { Normal- } \\
\text { weight }\end{array}$ & $\begin{array}{l}\text { Between } \\
18.5 \\
\text { and } 25\end{array}$ & 256 & $\begin{array}{l}107 \\
(41.8)\end{array}$ & $\begin{array}{l}149 \\
(58.2)\end{array}$ & $10(3.9)$ & 6 & 4 & $\begin{array}{l}18.99 \pm \\
2.919\end{array}$ & $63(24.6)$ & $16(6.3)$ & $20(7$. \\
\hline Overweight & $\begin{array}{l}\text { Between } \\
25 \text { and } \\
30\end{array}$ & 130 & $\begin{array}{l}75 \\
(57.5)\end{array}$ & $\begin{array}{l}55 \\
(42.3)\end{array}$ & $\begin{array}{l}21 \\
(16.2)\end{array}$ & 7 & 4 & $\begin{array}{l}20.94 \pm \\
4.446\end{array}$ & $36(27.7)$ & $1(0.8)$ & $15(11$ \\
\hline $\begin{array}{l}\text { Obesity } \\
\text { class I }\end{array}$ & $\begin{array}{l}\text { Between } \\
30 \text { and } \\
35\end{array}$ & 56 & $\begin{array}{l}32 \\
(57.1)\end{array}$ & $\begin{array}{l}24 \\
(42.9)\end{array}$ & $\begin{array}{l}12 \\
(21.4)\end{array}$ & 12 & 9 & $\begin{array}{l}21.88 \pm \\
5.387\end{array}$ & 19 (33.9) & $4(7.1)$ & $21(3 ;$ \\
\hline $\begin{array}{l}\text { Obesity } \\
\text { class II }\end{array}$ & $\begin{array}{l}\text { Between } \\
35 \text { and } \\
40\end{array}$ & 21 & $\begin{array}{l}14 \\
(66.7)\end{array}$ & $\begin{array}{l}7 \\
(33.3)\end{array}$ & $6(28.6)$ & 8 & 5 & $\begin{array}{l}21.90 \pm \\
5.567\end{array}$ & $6(28.6)$ & $1(4.8)$ & $6(28$. \\
\hline Total & & 502 & $\begin{array}{l}235 \\
(46.8 \%)\end{array}$ & $\begin{array}{l}267 \\
(53.2 \%)\end{array}$ & $\begin{array}{l}57 \\
(11.3)\end{array}$ & 7 & 4 & $\begin{array}{l}20.18 \pm \\
4.291\end{array}$ & $142(28.2)$ & $46(9.1)$ & 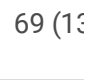 \\
\hline P-value & & & & & $P<C$ & 001 & 001 & 001 & 001 & $\mathrm{P}<0$ & 01 \\
\hline
\end{tabular}

Of 502 patients, 142 patients (28.2\%) developed nosocomial infection, $52(10.4 \%)$ of which were pulmonary infection, 28 (5.6\%) were urinary tract infection, 22 (4.4\%) were skin infection, 19 (3.8\%) were abdominal infection, 15 (3.0\%) were catheter infection, and $6(1.2 \%)$ were brain infection. A logistic regression model was constructed which led to the following results: The mortality rate in patients with abdominal infection, pulmonary infection, and skin infection were respectively 5.92, 4.73, and 3.77 times more and statistically significant (P-value $<0.05)$. The relationship between the mortality rate and urinary tract infection, catheter infection, and brain infection were not statistically significant.

The median for the duration of vasopressor-therapy and mechanical ventilation were 0 and 1, respectively. The Kruskal-Wallis test was used to compare the duration of vasopressor-therapy and the duration of mechanical ventilation in different BMI groups. The results of the Kruskal-Wallis test showed that the duration of vasopressor-therapy was highest in patients with a BMI between 35 and 40, and the least for patients with a BMI between 18.5 and 25 . The differences in vasopressor-therapy were statistically significant (P-value $<0.001)$. According to the results of the Kruskal-Wallis test, the mechanical ventilation duration was the lowest in patients with a BMI of 35 to 40 , with an average of 11.57 days, and for individuals with a BMI of 18.5 to 25 was the most with an average of 2.50 days. This difference was also statistically significant (P-value $<0.001)$.

Among the 502 patients, 140 patients (27.9\%) developed renal failure (OR = 8.75), $114(22.7 \%)$ developed respiratory failure $(\mathrm{OR}=5.41), 58(11.6 \%)$ developed heart failure ( $\mathrm{OR}=11.83), 30(6.0 \%)$ developed CNS dysfunction (OR = 4.58), $26(5.2 \%)$ developed hepatic failure $(\mathrm{OR}=5.23)$, and 13 patients $(2.6 \%)$ developed blood markers disturbance $(\mathrm{OR}=10.84)$, all of which were statistically significant $(\mathrm{P}$-value $<0.05)$. 
Investigating the association of waist circumference, BMI, and APACHE II score with the mortality rate, logistic regression was conducted considering the age and gender of the patients. The results showed a statistically significant association between waist circumference and mortality rate, in which for each cm increase in the waist circumference, the patients' chances of mortality increased by $1.15(\mathrm{R}=1.15,95 \% \mathrm{Cl}=1.03-1.29, \mathrm{P}-\mathrm{value}=0.014)$. Also, the association between APACHE II score and the mortality rate was statistically significant, as per each unit of increase in APACHE II score, the mortality rate increased by $2.79(\mathrm{OR}=2.79,95 \% \mathrm{Cl}=1.91-4.07, \mathrm{P}$-value $<0.001)$. The impact of $\mathrm{BMI}$ on mortality rate was not found statistically significant.

\section{Discussion}

The current study assessed the association of body mass index and mortality rate among 502 patients admitted to the ICU. In this study, the highest mortality rate was observed in patients with a BMI between 35 and 40 (obesity class II), and the lowest rate was observed in patients with a BMI between 18.5 and 25 (normal-weight patients).

Obesity is known to play a role in the development and progression of numerous disorders, many of which could easily lead to fatal outcomes [18]. Notwithstanding, there is a point of conflict whether BMI is a proper representation of obesity in predicting mortality-related outcomes. The evidence on the connection between BMI - as a phenomenon of obesity - and mortality rate are extremely conflicting, as some studies have shown no significant relation, while some others have shown an increase or decrease in patients' mortality [19-21]. In a prospective study conducted to evaluate the effect of obesity on the mortality of patients admitted to ICU in Saudi Arabia, the mortality rate in overweight critically ill patients was lower than patients with normal-weight, despite identical severity of the illness [22]. A retrospective study conducted in the United States determined that patients with $\mathrm{BMI}>40$ (obesity class III) and patients with $\mathrm{BMI}<20$ have a higher length of hospital stay [23]. They concluded that lower BMI is associated with an increased mortality rate and worsened functional status at the time of discharge. A cohort of 699 patients also demonstrated that the obese patients have lower in-hospital mortality, though, the findings were not witnessed among the older group of the obese patients, which suggests further studies to elaborate the possible connection between age, obesity, and fatal outcomes in intensive care units [24]. Nasraway et al. showed during a cohort study in the UK that BMI > 40 was an independent cause of death in ICUadmitted surgery patients. It was concluded that severe obesity is a direct and effective risk factor in the mortality of ICU patients in similar conditions regarding age, sex and severity of the disease [25]. Although our study lacked the group of BMls $>40$, the highest mortality rate was still observed in most obese patients.

On the other hand, many studies have claimed that there is no correlation between the BMI and mortality outcomes of critically ill patients. Supporting this claim, a recent study showed although obesity has a direct impact on reducing the need of intubation and inotropic support, there is no significant evidence of an increase or decreasing in patients' mortality [26]. Another study on 312 patients with sepsis and acute respiratory failure showed that even though overweight and obese patients have an increased length of stay in both hospital and ICU, BMI is independent of mortality rate [27]. Likewise, a study conducted by Lewis et al., on the patients admitted to an adult medical ICU with a more than 24 hours stay, presented that the overweight and obesity were not related to ICU mortality. Still, obesity was significantly associated with longer length of stay and increased comorbid illness [28]. Recent studies are intended to evaluate the issue in larger study populations, among different subgroups, and according to the etiology context [26, 29, 30]. A recent dose-response metaanalysis regarding the effect of BMI on the mortality of ICU-admitted patients showed that for each unit of increase in BMI (kg/m2), a $0.6 \%$ decrease in mortality rate is expected [31]. This study also discussed that while a BMI $>35$ is a dangerous feature in ICU-admitted patients, a BMI $<35$ can play a protective role against mortality. The reason behind conflicting results of different studies could be explained according to the differences in study designs, ethnicity, classification of BMI, comorbidities, differences in the type of ICU admission, and physiological severity of the illness.

The present study also showed that per each unit of increase in APACHE II score and waist circumference, the risk of mortality increases by 2.79 and 1.15 , respectively. These findings display that waist circumference could be a better predictive value than BMI. There are several available studies supporting the current finding. An observational study conducted by Paolini et al., the mortality of 403 patients admitted to the intensive care unit were evaluated. The results showed that unlike BMI, higher waist circumference is a risk factor of mortality in critically ill patients [32]. Also, a recent pooled analysis of eleven prospective cohort studies with a total of 650,000 participants with a median of nine-years follow-up, discussing the relation of waist circumference and mortality concluded that the higher waist circumference is significantly related to higher mortality, and even for patients with a normal BMI, waist circumference could still be a prognostic factor for risk assessment [33].

Regarding the association of BMI and hospital infection, the present study demonstrated that the patients with BMI $<18.5$ had the highest rate of hospital infection, while the normal-BMI patients had the lowest rate. A retrospective cohort study by Papadimitriou-Olivgeris et al. supports the current results [34]. The study, focused on the role of obesity in the prognosis of sepsis patients, revealed that obesity had a direct impact on some morbidities, including bloodstream infection and Klebsiella pneumonia colonization, concluding that obesity affects sepsis upon ICU admission. Regarding the association of high BMI and mortality in ARDS patients, studies showed interesting results which is known as obesity paradox. It means that morbid obese ARDS patients has a lower mortality compared to normal patients. In obesity, the high chest wall elastance could redistribute regional transpulmonary pressure, possibly reducing the potential negative effects of mechanical ventilation in an inhomogeneous lung [35]. However, any positive relationship between obesity and survival may be outweighed by the volume of data linking obesity with a great number of severe illnesses. Any residual uncertainty should not mean that physicians overlook the clear risk-lowering effects of weight reduction in obese individuals who are at a higher risk of different disorders and complication. In spite of the conflicting result for correlation of BMI and mortality, recent studies showed that waist circumferences is independent risk factor for mortality in critically ill patients and showed a significant negative association with mortality [36]. The results of this study also indicated that BMI could be associated with mortality, without considering waist circumference and APACHE score, but once these are considered as confounding factors, BMI does not affect mortality and only affects the morbidity of patients.

While the current study benefited from an adequate study duration and proper sample size, it had a limited follow-up duration. Therefore, further studies with more participants, longer follow-up duration, and with the evaluation of long-term outcomes among different BMI groups are suggested. Moreover, conducting 
studies based on specific types of admission (medical, surgical, or trauma) and on specific subgroups of age, sex and ethnicities may result in more explicit and clear findings.

\section{Conclusion}

Higher BMI as a representation of total body fat content, is associated with increased mortality in the general population. It seems that physicians should notice waist circumference in the assessment of obesity-related health risks, while considering individualized cut-off points for their patients in routine practice.

\section{Declarations}

\section{Authors' contribution:}

A.M: Study hypothesis, data collection, manuscript editing

F.K: data collection, data analysis, manuscript editing

MS.H: Data collection, initial drafting

A.l: data analysis, manuscript editing,

S.S: Study hypothesis, data collection,

All authors read and accepted the final version of manuscript

Declaration of conflict of interest: the authors declared no conflict of interest

Funding: Non

\section{References}

1. Boggs DA, Rosenberg L, Cozier YC, Wise LA, Coogan PF, Ruiz-Narvaez EA, et al. General and abdominal obesity and risk of death among black women. N engl j med. 2011;365:901-8.

2. Smith KB, Smith MS. Obesity statistics. Primary care: clinics in office practice. 2016;43(1):121-35.

3. Hales CM, Carroll MD, Fryar CD, Ogden CL. Prevalence of obesity and severe obesity among adults: United States, 2017-2018. 2020.

4. Charansonney OL, Després J-P. Disease prevention-should we target obesity or sedentary lifestyle? Nature Reviews Cardiology. 2010;7(8):468.

5. Flashner BM, Rifas-Shiman SL, Oken E, Camargo CA, Platts-Mills TJ, Workman L, et al. Obesity, sedentary lifestyle, and exhaled nitric oxide in an early adolescent cohort. Pediatr Pulmonol. 2020;55(2):503-9.

6. Bjorntorp P. Definition and classification of obesity. Eating disorders and obesity: A comprehensive handbook. $2002 ; 2$.

7. Piché M-E, Poirier P, Lemieux I, Després J-P. Overview of epidemiology and contribution of obesity and body fat distribution to cardiovascular disease: an update. Prog Cardiovasc Dis. 2018;61(2):103-13.

8. Kotsis V, Stabouli S, Papakatsika S, Rizos Z, Parati G. Mechanisms of obesity-induced hypertension. Hypertension research. 2010;33(5):386-93.

9. Vucenik I, Stains JP. Obesity and cancer risk: evidence, mechanisms, and recommendations. Ann N Y Acad Sci. 2012;1271(1):37.

10. Peters U, Suratt BT, Bates JH, Dixon AE. Beyond BMl: obesity and lung disease. Chest. 2018;153(3):702-9.

11. Mokdad AH, Ford ES, Bowman BA, Dietz WH, Vinicor F, Bales VS, et al. Prevalence of obesity, diabetes, and obesity-related health risk factors, 2001. Jama 2003;289(1):76-9.

12. Zampieri FG, Colombari F. The impact of performance status and comorbidities on the short-term prognosis of very elderly patients admitted to the ICU. BMC anesthesiology. 2014;14(1):59.

13. Sekulic AD, Trpkovic SV, Pavlovic AP, Marinkovic OM, llic AN. Scoring systems in assessing survival of critically ill ICU patients. Medical science monitor: international medical journal of experimental clinical research. 2015;21:2621.

14. Faruq MO, Mahmud MR, Begum T, Ahsan AA, Fatema K, Ahmed F, et al. A comparison of severity systems APACHE II and SAPS II in critically ill patients. Bangladesh Critical Care Journal. 2013;1(1):27-32.

15. De Jong A, Verzilli D, Sebbane M, Monnin M, Belafia F, Cisse M, et al. Medical versus surgical ICU obese patient outcome: a propensity-matched analysis to resolve clinical trial controversies. Critical care medicine. 2018;46(4):e294-301.

16. Utzolino S, Ditzel CM, Baier PK, Hopt UT, Kaffarnik MF. The obesity paradox in surgical intensive care patients with peritonitis. J Crit Care. 2014;29(5):887. e1-. e5.

17. Schetz M, De Jong A, Deane AM, Druml W, Hemelaar P, Pelosi P, et al. Obesity in the critically ill: a narrative review. Intensive care medicine. 2019:1-13.

18. Abdelaal M, le Roux CW, Docherty NG. Morbidity and mortality associated with obesity. Annals of translational medicine. 2017;5(7). 
19. Flegal KM, loannidis JP, Doehner W. Flawed methods and inappropriate conclusions for health policy on overweight and obesity: the Global BMI Mortality Collaboration meta-analysis. Journal of cachexia sarcopenia muscle. 2019;10(1):9-13.

20. Klatsky AL, Zhang J, Udaltsova N, Li Y, Tran HN. Body mass index and mortality in a very large cohort: is it really healthier to be overweight? The Permanente Journal. 2017;21.

21. Banack HR, Kaufman JS. The obesity paradox: understanding the effect of obesity on mortality among individuals with cardiovascular disease. Preventive medicine. 2014;62:96-102.

22. Aldawood A, Arabi Y, Dabbagh 0. Association of obesity with increased mortality in the critically ill patient. Anaesthesia intensive care. 2006;34(5):62933.

23. Tremblay A, Bandi V. Impact of body mass index on outcomes following critical care. Chest. 2003;123(4):1202-7.

24. Trivedi V, Jean RE, Genese F, Fuhrmann KA, Saini AK, Mangulabnan VD, et al. Impact of Obesity on Outcomes in a Multiethnic Cohort of Medical Intensive Care Unit Patients. Journal of Intensive Care Medicine. 2018;33(2):97-103.

25. Nasraway SA Jr, Albert M, Donnelly AM, Ruthazer R, Shikora SA, Saltzman E. Morbid obesity is an independent determinant of death among surgical critically ill patients. Critical care medicine. 2006;34(4):964-70.

26. Davis ET, Xie L, Levenbrown Y. Impact of Obesity on Outcomes in Critically III Children. Journal of Parenteral Enteral Nutrition. 2018;42(5):864-71.

27. Juarez E, Edriss H, Lear M, Sanchez A, Yang S, Nugent K. The association between body mass index and outcomes in patient with sepsis and acute respiratory failure. The Southwest Respiratory Critical Care Chronicles. 2019;7(31):13-23.

28. Lewis OD, Ngwa J, Kibreab A, Phillpotts M, Thomas A, Mehari A. Body Mass Index and Intensive Care Unit Outcomes in African American Patients. Ethn Dis. 2017;27(2):161-8.

29. O'Dene Lewis JN, Kibreab A, Phillpotts M, Thomas A, Mehari A. Body mass index and intensive care unit outcomes in african american patients. Ethn Dis. 2017;27(2):161.

30. Pauzenberger R, Radtke C, Ederer IA, Hacker S, Waldmann A, Sternat N, et al. Does obesity impact the outcome of severely burned patients? Int Wound J. 2020;17(2):380-6.

31. Khalooeifard R, Djafarian K, Safabakhsh M, Rahmani J, Shab-Bidar S. Dose-Response Meta-Analysis of the Impact of Body Mass Index on Mortality in the Intensive Care Unit. Nutrition in Clinical Practice.n/a(n/a).

32. Paolini J-BM, Mancini J, Genestal M, Gonzalez H, McKay RE, Samii K, et al. Predictive value of abdominal obesity vs. body mass index for determining risk of intensive care unit mortality. Critical care medicine. 2010;38(5):1308-14.

33. Cerhan JR, Moore SC, Jacobs EJ, Kitahara CM, Rosenberg PS, Adami H-O, et al. A Pooled Analysis of Waist Circumference and Mortality in 650,000 Adults. Mayo Clinic Proceedings. 2014;89(3):335 - 45.

34. Papadimitriou-Olivgeris M, Aretha D, Zotou A, Koutsileou K, Zbouki A, Lefkaditi A, et al. The role of obesity in sepsis outcome among critically ill patients: a retrospective cohort analysis. BioMed research international. 2016;2016.

35. Zhi G, Xin W, Ying W, Guohong X, Shuying L. Obesity paradox in acute respiratory distress syndrome, A systematic review and meta analysis. PLOS ONE. 2016;11(9):e0163677. doi:10.1371/journal.pone.0163677.

36. Cho GJ, Yoo HJ, Hwang SY, Choi J, Lee K-M, Choi KM, et al. Differential relationship between waist circumference and mortality according to age, sex, and body mass index in Koreans with age of 30-90 years; a nationwide health insurance database study. BMC Med (2018) 16:131

https://doi.org/10.1186/s12916-018-1114-7. 